\title{
CAPABILITIES OF LIDAR- AND SATELLITE DATA IN ASSESSING THE DRIVERS OF AVIAN DIVERSITY IN A FRAGMENTED LANDSCAPE
}

\author{
Markus Melin ${ }^{1}$, Shelley Hinsley ${ }^{2}$, Richard Broughton ${ }^{2}$, Paul Bellamy ${ }^{3}$, Ross Hill $^{1}$ \\ 1 Bournemouth University, Department of Life and Environmental Sciences., United Kingdom. \\ 2 Centre for Ecology and Hydrology, Wallingford, United Kingdom. \\ 3 The Royal Society for the Protection of Birds (RSPB), Center for Conservation Science, United Kingdom
}

\begin{abstract}
In modern landscapes, small habitat patches such as woodlands isolated in an agricultural matrix, can be important refuges for wildlife. However, their value as habitat may be compromised by their size and thus knowledge of how habitat structure influences habitat quality is vital to maximize species diversity.

This study examined the factors driving avian diversity in four small woods in an agricultural landscape, and how accurately remote sensing (RS) metrics were able to quantify this. Linear mixed-effect models were used to combine annual breeding bird census data with data of habitat structure from satellite images and airborne lidar. The aims were firstly to examine the drivers of bird diversity, and secondly to reveal the strengths and weaknesses of the compared RS datasets in quantifying them.

The results showed that, at first, bird diversity increased significantly towards the edges, being driven in part by vegetation structure. The amount of understorey vegetation was the most significant driver of diversity, due to which lidar-based models outperformed satellite-based ones. In general, lidar metrics correlated strongly with bird diversity, but such relationships were not discovered with satellite image metrics. The results indicate that the drivers of diversity, especially in fragmented woodlands may be too fine-scaled to be studied without sufficient consideration of the structural component of vegetation, which was proven to be attainable from lidar data.
\end{abstract}

Index Terms - lidar, bird diversity, satellite, fragmentation, landscape ecology, habitat

\section{INTRODUCTION}

Habitat fragmentation has long been known to affect negatively on biodiversity and a common example of today's fragmented landscape is a mosaic of woodland patches scattered in a predominantly agricultural environment [1].

Birds form a group of species that has been studied widely in fragmented landscape to examine, for example, the state of ecosystems and their biodiversity or the loss of habitat quality [2], because their diversity has been documented to correlate with overall biodiversity [3].
However, maintaining diversity in fragmented landscapes is challenging since, in addition to not being able to move between habitat patches, certain species have minimum area requirements, for example, for their breeding habitat, which makes some patches inhabitable based on their size alone [4]. Therefore, a crucial part of maintaining biodiversity in these kinds of fragmented landscapes is done through maintenance of desirable features of, for example, vegetation structure that can maximize a habitat's suitability for as many dependent species as possible.

To tackle the issue, RS methods such as aerial and satellite imagery have been used to assess not just landscape fragmentation, but also the ecology of bird species within the fragments $[5,6,7]$. These methods, however, may not suffice as the importance of $3 \mathrm{D}$ vegetation structure is known [8], and furthermore it has been suggested that the drivers of diversity in vulnerable landscapes such woodland fragments and their edges), are too fine-scaled to be studied without acknowledging the structural component of vegetation in enough detail [7]. This has been done for numerous bird species with airborne lidar data [9]. However, studies contrasting the performance of different RS datasets, especially in fragmented landscapes where species have little chances of migrating, are rare.

The present study combines airborne lidar data and satellite image data with field data from bird surveys conducted in woodland fragments scattered within a agricultural environment. The aims are 1.) to examine the drivers of bird species diversity in the woodland patches, 2.) to test how well the different optical and lidar-based metrics can quantify this and research their potential strengths and weaknesses over one another. The results are also discussed in relation to habitat management; assessing whether the results provided by either of the RS methods detailed enough to guide practical habitat management.

\subsection{Study area}

\section{MATERIALS AND METHODS}

The target sites were four woods located in Cambridgeshire, in eastern England $\left(52^{\circ} 25^{\prime} 13.5^{\prime \prime} \mathrm{N}, 0^{\circ} 12^{\prime} 34.0^{\prime \prime} \mathrm{W}\right)$, in a landscape dominated by intensive arable agriculture. The four woods comprise: Riddy Wood (9.4 ha), Lady's Wood 
(8.4 ha), Raveley Wood (7.2 ha) and Gamsey Wood (4.9 ha) (Figure 1).

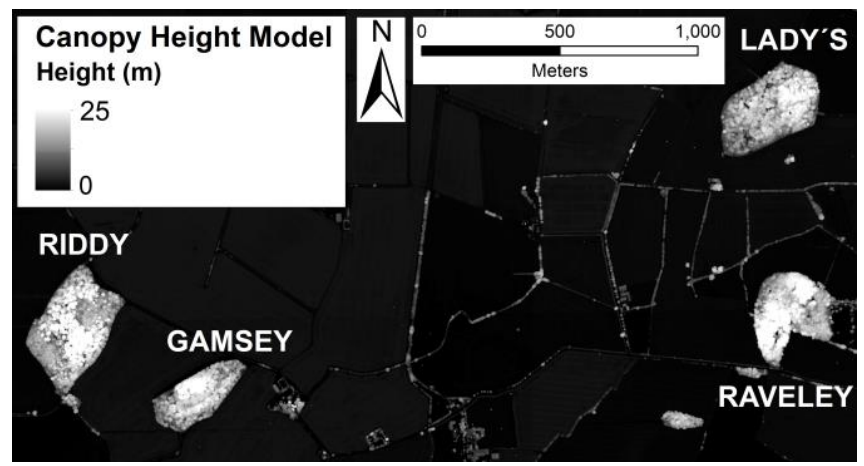

Figure 1. The study area displayed over a lidar-based canopy height model.

\subsection{Bird data collection}

Each wood was visited four times from late March to the end of July during the years 2012 and 2015. Visits started shortly after dawn and avoided weather conditions (i.e. rain and strong winds) likely to depress bird activity. Birds were recorded using a spot mapping technique [10] based on the method of the Common Birds Census of the British Trust for Ornithology [11].

Each wood was searched systematically using a route designed to encounter all breeding territories. All birds seen or heard were recorded on a map of the wood. These locations were later digitized into a GIS system. Individuals were recorded only once and in cases where the same bird was suspected to be observed twice, the second observation was omitted. Only adults were included in the analysis because the locations of dependent young are not independent from their parents. A complete list of the 28 species included in the analysis is given in [7].

\subsection{Remote sensing data}

Lidar data used in this study were collected with a Leica ALS50-II scanner during leaf-on conditions on June $1^{\text {st }}$, 2014. The scanning was done from a fixed-wing aircraft from an altitude of ca. 2100 meters. The average pulse density in the study woods was 2.7 pulses per $\mathrm{m}^{2}$. The ALS50-II device captures a maximum of four return echoes for one emitted laser pulse, and all of these echo categories were used in this study.

The satellite imagery data consisted of one Landsat 8 OLI image captured on May $17^{\text {th }} 2014$ and one Sentinel $2 \mathrm{~A}$ image captured on June $6^{\text {th }} 2016$. Sentinel images from earlier years were not available due to poor cloud conditions. However, no management activities had been carried out in the forest between the survey periods and RS data acquisitions.

\subsection{Creating variables of avian diversity and habitat structure}

For analysis, the four woods were divided into cells with an area of ca. $215 \mathrm{~m}^{2}(\mathrm{n}=1393)$. Due to the irregular shapes of the wood boundaries, the cell shapes were allowed to vary from perfect squares as cells were to be equal sized and not allowed to exceed the woodland boundaries However, care was taken to ensure similar cell shape and depth, especially along the edge to prevent bias in relation to bird observation probability. Next, cell-specific metrics of bird diversity and vegetation structure were calculated (Table 1).

Table 1. The metrics of avian diversity and habitat structure

\begin{tabular}{|c|c|}
\hline \multicolumn{2}{|c|}{$\begin{array}{l}\text { PREDICTOR VARIABLES } \\
\end{array}$} \\
\hline Variable & Description \\
\hline p_veg & $\begin{array}{l}\% \text { of lidar returns coming from above } 0.5 \text { meters } \\
\text { (vegetation hits). }\end{array}$ \\
\hline CanopyCover_X* & $\begin{array}{l}\% \text { of lidar returns coming from above } \mathrm{X} \text { meters } \\
\text { calculated from all returns. }\end{array}$ \\
\hline ShrubCover_X* & $\begin{array}{l}\% \text { of lidar returns between } 0.5 \text { and } \mathrm{X} \text { meters } \\
\text { calculated only from the returns below } \mathrm{X} \text { meters. A } \\
\text { ShrubCover } X \text { value of } 0.6 \text { means that } 60 \% \text { of the } \\
\text { returns coming from below } \mathrm{X} \text { meters hit vegetation } \\
\text { not the ground. }\end{array}$ \\
\hline $\begin{array}{l}h \_m a x, h \_a v g, \\
h \_s t d\end{array}$ & $\begin{array}{l}\text { Maximum and average height of the lidar returns } \\
\text { and their standard deviation. }\end{array}$ \\
\hline EdgeDistance & $\begin{array}{l}\text { The Euclidean distance (in meters) from the } \\
\text { centroid of this cell to the nearest edge }\end{array}$ \\
\hline NDVI & Normalized difference vegetation index \\
\hline DVI & Difference vegetation index \\
\hline$S R$ & Simple ratio \\
\hline$R S R$ & Reduced simple ratio \\
\hline Band values & $\begin{array}{l}\text { Avg, min, max and median values calculated for } \\
\text { Red, Green, Blue,SWIR and NIR bands. }\end{array}$ \\
\hline \multicolumn{2}{|c|}{ RESPONSE VARIABLES } \\
\hline Variable & Description \\
\hline ShannonD & Shannon's index of diversity \\
\hline SpeciesN & Amount of species observed in the area of this cell \\
\hline \multicolumn{2}{|c|}{$\begin{array}{l}\text { *four cut-off values }(4,6,8 \text { and } 10 \text { meters) were used for assessing } \\
\text { the density of shrub-and canopy cover. This equals to eight different } \\
\text { variables, four for shrub cover, four for canopy cover. }\end{array}$} \\
\hline
\end{tabular}

\subsection{Modelling}

For analysis, linear mixed-effect models were created for each of the response variables (Table 1). The individual woods were used as the random effects due to differing shapes and forest structures. Two sets of models were fitted to the data. The first models quantified the most significant predictors of bird diversity out of those listed in Table 1. The second models were fitted into subset of the data: they only included cells adjacent to the woodland edge. The second models were assumed to bring out the RS methoddependent differences more clearly as the potential effect of edge distance was now excluded and potential differences were caused by a varying vegetation structure along the edge.

Variable selection for all the models was achieved by an exhaustive search where the single most significant 
variable was first added to the model, after which the process was iterated until no more variables could have been added to the model; the final model was made of only significant $(\mathrm{p}<0.05)$ variables.

Spatial autocorrelation was noticed to be present in the immediate neighborhood of a cell and it was accounted for by a linear correlation structure using the built-in options of the R package nlme. All the modeling and analysis was done in $\mathrm{R}$ with the package nlme, and with ggplot 2 and cowplot for visualizations.

\section{RESULTS}

\subsection{Wood-level models}

The first clear finding was that the single most significant driver of bird diversity was edge distance: as distance to the edge decreased, bird diversity increased (with both metrics of diversity).

This effect, however, was partly being driven by vegetation structure and the lidar models were able to capture this: shrub vegetation was more abundant at the edge, which was partly responsible for attracting more bird species towards the edge. Indeed, after the variable selection process, EdgeDistance was joined by the two best lidar predictors $p_{-}$veg and CanopyCover_6. When all the predictor variables were pooled together, the variable selection resulted in exclusion of all the satellite-based metrics. Without lidar metrics, the best satellite-based predictor of diversity was the NDVI (from Sentinel-2), but it did not correlate with either of the diversity metrics $\left(\mathrm{R}^{2}=\right.$ $0.06, \mathrm{p}>0.05)$. Figure 2 illustrates the relationship between species richness $(\operatorname{Species} N)$ and the single most significant lidar (A.) and satellite based predictors (B.).
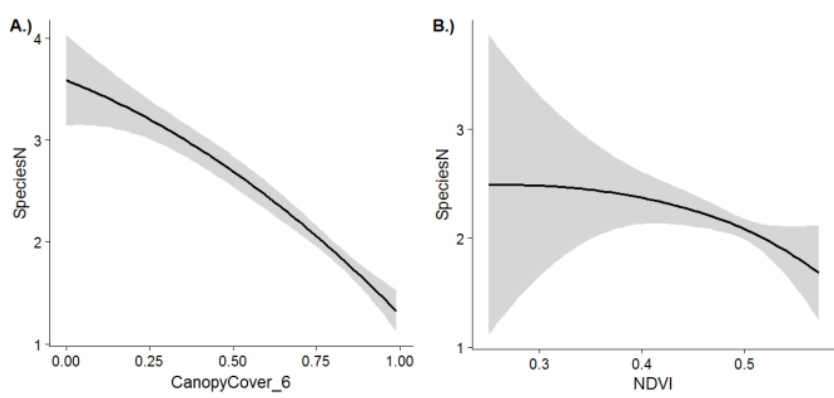

Figure 2. The relationships between CanopyCover_6 (A) and NDVI (B.) with species richness $(\operatorname{Species} N)$. The grey polygons around the lines depict the standard error.

\subsection{Edge models}

At the edge, the best lidar model was made up of only one predictor: ShrubCover_4 (i.e. density of vegetation between the ground and $4 \mathrm{~m}$ ). As with the wood-level models, satellite-based predictors never replaced nor joined the best lidar predictor. Outside the lidar variables, NDVI (Sentinel2) was again the best satellite-based predictor, but with no true relationship with the diversity metrics $\left(\mathrm{R}^{2}=0.01\right)$.
Figure 3 illustrates the relationship of diversity and the single most significant predictors from both lidar and satellite models.
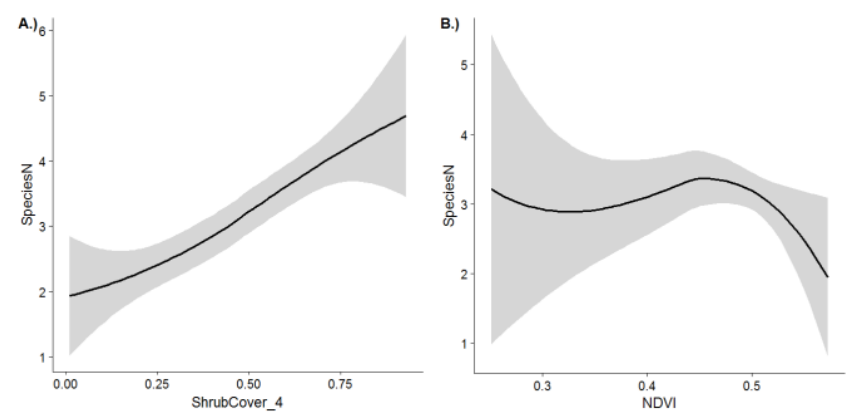

Figure 3. The relationships between ShrubCover_4 (A.) and NDVI (B.) with species richness (SpeciesN) along the woodland edges. The grey polygons around the lines depict the standard error.

The difference between the lidar- and satellitebased models was clear and it was due to the drivers of bird diversity being related to the density of the understorey layer. A further illustration of the situation is given in Figure 4 where view A shows the profile of vegetation in the site with the lowest $\operatorname{Species} N$ values and view B shows that from the site with the highest Species $N$. Where site A lacked understorey vegetation below $4 \mathrm{~m}$, this was very dense at site $\mathrm{B}$, thus supporting high avian diversity.

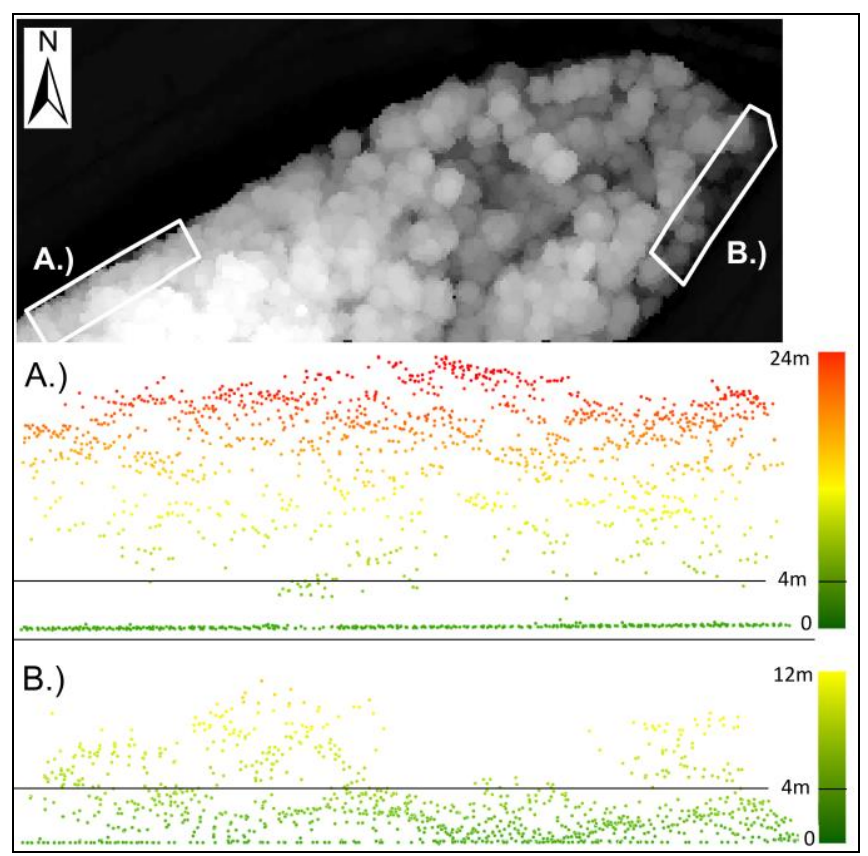

Figure 4. Vegetation profile of two sites at Gamsey Wood's edge with the lowest (A) and highest values for species richness. The three cells in site $\mathrm{A}$ had Species $\mathrm{N}$ values from 0 to 2 while those in site B had values from 9 to 12 . 


\section{DISCUSSION}

As noted by [4], an abrupt change in vegetation structure in an isolated woodland patch may lead to a permanent loss of certain species as the chances of migration are low. In the study landscape, the deforestation has happened centuries ago meaning that the wildlife has adapted to the current situation of fragmentation. This further underlines the significance of knowing what are the key features that sustain high diversity in even the comparably small woods.

The results showed that the main drivers were related to the 3D structure of vegetation (as ecologists have suggested for decades). A keyword search in the Web of Science (http://wok.mimas.ac.uk/), however, reveals that 'satellite imagery' dominates the scientific literature in relation to 'conservation' or 'ecology'. It was effectively shown here that two common satellite image types were not able to capture the drivers of avian diversity, which was related to comparably detailed 3D properties of vegetation. Lidar, on the other hand, succeeded in the same task. In addition, the results gained from the lidar based analysis were practical as they can be directly implemented by habitat managers: avian diversity in small woods can be maximized by maintaining a diverse vegetation structure across the wood and especially a well-developed shrub layer and a dense understorey along the edge. Indeed, edge distance alone was not responsible for high avian diversity. As Figure 4 shows, an edge without the understorey was effectively avoided. Even if it had been significant, a positive relationship between NDVI and bird diversity would have been hard to translate into management recommendations.

This study and its predecessor [7] were joint efforts between ecologists, conservationists and remote sensing specialists, resulting in a research setting where lidar data were used to gain information about those features of vegetation known to be vital for the target birds in the target environemtn. It is of vital value for future conservation that the potential aid provided by remote sensing methods such as lidar, is utilized to its full potential. This, in turn, is dependent on practical, hands-on collaboration across scientific disciplines.

\section{ACKNOWLEDGEMENTS}

The corresponding author is funded by Finnish Cultural Foundation's personal grant (Suomen Kulttuurirahasto www.skr.fi/en) applied via the Foundation's Post Doc Pool (http://www.postdocpooli.fi/?lang=en). Bird data collection was supported by the Wildlife Trust for Bedfordshire, Cambridgeshire and Northamptonshire. Airborne lidar data was acquired by Natural Environment Research Council's (NERC) Airborne Research Facility (NERC ARF).

\section{REFERENCES}

[1] P.F. Donald, R.E. Green, M.F. Heath, Agricultural intensification and the collapse of Europe's farmland bird populations, Proceedings of the Royal Society B 268, 25-28, 2001.

[2] R.J. Fuller, Birds and habitat: relationships in changing landscapes, Cambridge University Press, Cambridge, 2012.

[3] R.D. Gregory, and A. van Strien, Wild bird indicators: using composite population trends of birds as measures of environmental health, Ornithological Science 9, 3-22, 2010.

[4] S.A. Hinsley, P.E. Bellamy, I. Newton, and T.H. Sparks, Habitat and landscape factors influencing the presence of individual breeding bird species in woodland fragments, Journal of Avian Biology 26(2), 94-104, 1995.

[5] D.C. Duro, J. Girard, D.J. King, L. Fahrig, S. Mitchell, K. Lindsay, and L. Tischendorf, Predicting species diversity in agricultural environments using Landsat TM imagery, Remote Sensing of Environment 144, 214-255, 2014.

[6] J. Hofmeister, J. Hošek, M. Brabec, and R. Kočvara, Spatial distribution of bird communities in small forest fragments in central Europe in relation to distance to the forest edge, fragment size and type of forest, Forest Ecology and Management 401, 255-263, 2017.

[7] M. Melin, S.A. Hinsley, R.K. Broughton, P. Bellamy, and R.A. Hill, Living on the edge - utilizing lidar data to assess the importance of vegetation structure for avian diversity in fragmented woodlands and their edges. Landscape Ecology, DOI: https://doi.org/10.1007/s10980018-0639-7, 2018.

[8] R.H. MacArthur, and J.W. MacArthur, On bird species diversity, Ecology 42(3): 594-598.

[9] A.B. Davies, and G.P. Asner, Advances in animal ecology from 3D-LiDAR ecosystem mapping, Trends in Ecology and Evolution 29(12): 681-691, 2014.

[10] C.J. Bibby, N.D. Burgess, and D.A. Hill, Bird Census Techniques, Academic Press, London, 1992.

[11] J.H. Marchant, BTO common birds census instructions, British Trust for Ornithology, Tring, 1983. 